\title{
Hip involvement in children with enthesitis related arthritis (ERA) is associated with poor outcomes in adulthood
}

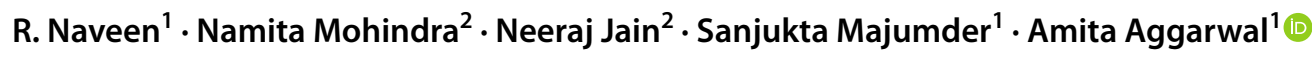

Received: 22 March 2021 / Revised: 28 May 2021 / Accepted: 31 May 2021 / Published online: 25 June 2021

(c) International League of Associations for Rheumatology (ILAR) 2021

\begin{abstract}
Background The data on long-term outcome in enthesitis-related arthritis (ERA), the commonest category of JIA in India, is scant. Thus, we studied outcomes of ERA in a resource-constrained setting.

Methods Patients with ERA (ILAR classification) ( $\geq 5$ years of disease and $\geq 18$ years) were included. Data on clinical features, Bath indices (BASMI, BASDAI, BASFI), ASDAS, and health assessment questionnaire-disability index (HAQ-DI) was collected. X-ray pelvis including hips was obtained and compared with baseline X-ray for progression of sacroiliitis and hip arthritis. Fulfillment of adult criteria of spondyloarthropathy (SpA) were also assessed.

Results Seventy-three 73 patients (72 males) of median age 20 (18-23) years and disease duration 8 (5.5-11) years were recruited. There was delay in diagnosis of 4 (1.75-6) years. Thirty-nine (53\%) had BASDAI $\geq 4$ and $63(91 \%)$ had ASDAS-CRP $>1.3$. Two-third (60\%) had functional disability (HAQ-DI $\geq 0.5$ ). Poor outcome (BASDAI $\geq 4$, ASDAS $>2.1$, BASFI $>0.9$, or HAQ-DI $\geq 0.5)$ was seen in three-fourths $(n=56.76 \%)$ of patients and was associated with hip involvement, HLA-B27 positivity, and fulfillment of axial ASAS criteria. Sixty-seven (91\%) patients fulfilled axial ASAS criteria, while $71(97 \%)$ fulfilled peripheral ASAS criteria.

Overall, $81 \%$ had X-ray sacroiliitis and 37\% had hip involvement. Nearly half (46.6\%) and one-fourths (25\%) of the patients had X-ray sacroiliitis and hip arthritis progression, respectively. Those with X-ray hip arthritis had longer delay in diagnosis (6 vs 3 years), higher Bath indices, ASDAS, and HAQ-DI. Hip arthritis correlated with radiological sacroiliitis $(r=0.301)$. Fulfillment of modified NY criteria was seen more often in patients with hip arthritis (95 vs 63\%; $<<0.002$ ).

Conclusion Most ERA patients had active disease in adulthood. Hip involvement, axial involvement, and HLA-B27 positivity were predictors of poor outcome.

\section{Key Points}

- Almost $90 \%$ of adults with ERA had active disease even after 8 years of disease.

- Poor outcomes were seen in three-fourths of patients and hip involvement, presence of HLA B27, and axial involvement were the predictors of poor outcome.
\end{abstract}

Keywords Arthritis $\cdot$ HLA-B27 $\cdot$ Juvenile $\cdot$ Outcomes $\cdot$ Radiography $\cdot$ Sacroiliitis $\cdot$ Spondyloarthritis

Amita Aggarwal

aa.amita@gmail.com

1 Department of Clinical Immunology and Rheumatology, Sanjay Gandhi Postgraduate Institute of Medical Sciences, Lucknow 226014, India

2 Department of Radiodiagnosis, Sanjay Gandhi Postgraduate Institute of Medical Sciences, Lucknow 226014, India

\section{Introduction}

Juvenile idiopathic arthritis (JIA) is a heterogeneous disease with seven different categories according to ILAR classification [1]. Enthesitis-related arthritis (ERA) is a subset of JIA that presents with lower limb arthritis usually in boys older than 6 years of age. The other features include enthesitis and tarsitis. About 70-75\% of these children are HLA B-27 positive. Over time, some of these children develop features of involvement of the spine in the form of low backache, clinical, and radiological sacroiliitis [2]. 
Recent studies using MRI of sacroiliac joints have found that almost one-third of children have acute sacroiliitis as evidenced by bone marrow edema at onset of disease [3]. Thus, it has a strong resemblance to adult spondyloarthropathies. Previous data from our center 10 years ago in 49 patients showed that at a median follow-up of 6 years, only $6 \%$ were in remission and one-third had reduced spinal mobility [4]. There are only a few follow-up studies on longterm outcomes of ERA. A cohort of 55 ERA patients from Norway who were followed up for nearly 15 years showed lower levels of physical functioning, poorer physical health, when compared with JIA patients with oligoarthritis or polyarthritis, and healthy controls. Though $44 \%$ with a diagnosis of ERA were in remission at the end of follow-up, $75 \%$ had restricted lumbar flexion and $35 \%$ had radiological sacroiliitis [5].

Adult outcome measures can be employed to assess the disease progression in JIA-ERA patients as they become adults. The Bath indices (Bath Ankylosing Spondylitis Metrological Index BASMI, Disease Activity Index BASDAI, Functional Index BASFI) [6], ASDAS (Ankylosing Spondylitis Disease Activity Score-ESR and CRP) [7], and HAQDI (Health Assessment Questionnaire Disability Index) [8] assess various domains like disease activity, function, and disability. The Assessment of Spondyloarthritis International Society (ASAS) has made recommendations for assessment of the outcome of SpA [9]. For radiological assessment of spine in adults, there are many scores available [10]. However, in children, the spine is less often involved and hip joint is more often involved; thus, those scores may not be useful in ERA.

ERA is the most common category of JIA seen in India [11] and constitutes 30-40\% of children seen in our clinic with JIA [12]. Even in the multinational cross-sectional observation cohort, ERA was found to be more common in South-East Asians (29\%) [13]. In contrast, it constitutes only 5-7\% of JIA in Caucasians [13]. As there is a paucity of data on the outcome of children with ERA in adulthood, we planned to study the long-term outcome (functional outcome, development of axial symptoms, limitation of spine mobility, sacroiliitis (clinical and radiological), hip joint damage, and frequency of total hip replacement), and the factors that predict poor outcome.

\section{Methods}

Patients Patients with ERA satisfying ILAR classification criteria, having $>5$ years of disease and above the age of 18 years, were included in the study [1]. There are 962 ERA patients (88females) enrolled in our clinic from 1998 to 2020 . Of them, 329 patients were now $>18$ years of age and had $\geq 5$ years of disease which were eligible for the study. Among them, 117 patients neither had complete contact detail nor did they visit the hospital during the study period. Among the remaining 212, in 72 patients, we did not have baseline pelvis $\mathrm{X}$-ray as the physician in-charge had not ordered it. All 140 were invited to participate and 73 of them visited the clinic between January 2019 and March 2020 and were included in the study. Due to COVID-19 pandemic, outpatient clinics were closed after that; hence, more patients could not be recruited. Informed consent was obtained from the patients.

Data on clinical features, Bath indices (BASDAI, BASFI, BASMI) [6], ASDAS [7], and HAQ DI [8] were collected. Bath Ankylosing Spondylitis Disease Activity Index (BASDAI) is a tool designed to assess disease activity. It includes 5 symptoms fatigue, spinal pain, peripheral pain, enthesitis, and morning stiffness assessed on a $0-10$ scale followed by a calculation of a composite score. Bath Ankylosing Spondylitis Metrology Index (BASMI) looks at the limitation in movement in the lumbar, thoracic, and cervical spine and hip joints. Bath Ankylosing Spondylitis Functional Index (BASFI) has 10 questions on functions affected in these patients measured on a VAS of $0-10$ and then a summary score is calculated. The Health Assessment Questionnaire (HAQ) assesses functions in 8 domains of daily routine activity on a scale of $0-3$ and then an average score is calculated [8].

Clinical details Baseline clinical details at first visit included history, examination findings, X-ray pelvis, ESR, CRP, hemogram, and HLA-B27. MRI at baseline was done in only a few patients. Consecutive patients who were willing to participate were recruited. Their cumulative clinical manifestations over the follow-up period were recorded and retrieved from their files. Clinical details on enthesitis, inflammatory back pain (IBP), uveitis, and clinical hip involvement were recorded. The treatment received and the disease activity were also recorded. Uveitis was considered based on history and evaluation by an ophthalmologist.

Radiology X-ray of the pelvis including hips was obtained and compared with baseline X-ray available at the first visit to our hospital for progression of radiological sacroiliitis and hip arthritis. The X-rays were assessed by two radiologists who were blinded to the clinical details of the patients. Radiological sacroiliitis was graded according to modified New York criteria [9] into 4 stages: grade 1, a suspicious blurring of joint margins; grade 2, minimal sclerosis with some erosion; grade 3, definite sclerosis on both sides of joint, severe erosions with a widening of joint space with or without ankylosis; grade 4, complete ankylosis. 
Plain radiograph of the hip was reviewed for reduction of joint space, osteophytes, sclerosis, altered femo$\mathrm{ral} /$ acetabular contour, and protrusion acetabuli and was graded into 4 grades [14]: grade 1, possible joint space narrowing and subtle osteophytes; grade 2, definite joint space narrowing, defined osteophytes, and some sclerosis, especially the acetabular side; grade 3, marked joint space narrowing, small osteophytes, some sclerosis, and cyst formation and deformity of femoral head and acetabulum; grade 4, gross loss of joint space with above features plus large osteophytes and increased deformity of femoral head and acetabulum. Radiological sacroiliitis progression was defined as increase of 2 grade in radiological sacroiliitis (can be unilateral 2 or bilateral 1 grade or more progression). Progression of hip involvement was defined similarly.

MRI with T1W, T2W, STIR, and post-gadolinium T1W pulse sequences was done for sacroiliac joints and hip joints. Sacroiliitis changes were assessed as per ASAS MRI consensus definitions [15]. Acute sacroiliitis is defined by 2 foci of bone marrow (BM) edema/osteitis in a single cut or 1 focus of BM edema/osteitis in 2 consecutive cuts. An isolated presence of synovitis, capsulitis, and enthesitis is not enough to define acute sacroiliitis. Chronic changes looked for are subchondral sclerosis, erosions, fat replacement of $\mathrm{BM}$, syndesmophytes, and ankylosis of joint.

Laboratory tests Five milliliters of blood was collected in EDTA tubes. DNA was extracted by salting out technique. The presence of HLA B27 was analyzed using ARMS-PCR by the previously described method [16]. CRP was measured by Nephelometry.

Outcomes Progression of radiological sacroiliitis by X-ray was the primary outcome. Secondary outcomes were (a) persistence of active disease (BASDI $\geq 4)$ and (ASDASCRP > 1.3) in adulthood; (b) fulfillment of adult SpA criteria (both ASAS axial spA [7, 17] and modified New York criteria [18]); and (c) predictors and associations of poor outcomes in adulthood. Poor outcome was defined as presence of BASDAI $\geq 4$ [19], or ASDAS-CRP $\geq 2.1$ [7] or BASFI $\geq 0.9$ [17] or HAQ-DI $\geq 0.5$ [8] for disease activity, functionality, or disability, respectively.

Statistical analysis Descriptive data were presented as the median and interquartile range (IQR). Comparison between groups was done with Mann-Whitney U test for scale variables and Chi-square for categorical variables. Predictors of outcome were analyzed by comparing patients with poor outcome vs good outcome by univariate and multivariate analysis (binary logistic regression) after imputation of missing variables. SPSS version 20 was used. STROBE checklist [20] was followed for reporting results.
Sample size With an effect size of $30 \%$ estimated by progression of sacroiliitis from previous study [5] and alpha error of $5 \%$, power $80 \%$, the sample size calculated was calculated to be 64 using $\mathrm{G}^{*}$ Power $^{\mathrm{TM}}$ version 3.1.9.4.

Ethics Ethics committee consent was obtained from Sanjay Gandhi postgraduate institute of medical sciences ethics board (2018-161—DM-EXP-3).

\section{Results}

Seventy-three patients (72male) of median age 20 [18-23] years and median disease duration of $8(5.5-11)$ years were recruited. There was a delay in diagnosis of $4(1.75-6)$ years. On average, $0.65(0.09-2)$ years of school years were lost due to the disease. Two-third (62\%) had studied up to high school only. Very few did graduation (32\%) and a fewer were employed (17, 23\%).

Arthritis was seen in 94\%, and enthesitis in 90\%. Inflammatory back pain was present in $91 \%$ with the median time of start of IBP being $0(0-24)$ months after disease onset. Clinical sacroiliitis (59\%), tarsitis (59\%), clinical hip joint involvement (31\%), and uveitis (18\%) were seen in fewer patients. HLA B27 was positive in 56/58 (98\%). Two-third (71\%) were on DMARDs and one-fifth $(27 \%)$ were on NSAIDs alone. TNF inhibitor was used by only 2 patients (Table 1).

One-half $(\mathrm{n}=39,53 \%)$ had BASDAI $\geq 4$ and nearly all $(\mathrm{n}=63,91 \%)$ had ASDAS-CRP $>1.3$. Median CRP was $2.31(0.74-4.82) \mathrm{mg} / \mathrm{dl}$ and median ESR was $24.5(14.7-40)$ $\mathrm{mm} / \mathrm{h}$. Two-thirds (60\%) had functional disability (HAQ$\mathrm{DI} \geq 0.5)$ and median BASFI was $1.6[1,2]$.

\section{Sacroiliitis development and progression}

Two-third $(47,64 \%)$ had radiological sacroiliitis to begin with and four-fifth $(59,81 \%)$ had developed radiological sacroiliitis at the time of recruitment over a span of 3.5 (2.5-5.5) years. Nearly half $(34,46.6 \%)$ of the patients had radiological progression in sacroiliitis. Patients with radiological sacroiliitis had higher CRP (2.5 vs $1 \mathrm{mg} / \mathrm{dl})$ and more hip arthritis (44 vs 7\%, p 0.01) than those without it. They also had higher BASMI (1.6 vs 1.1, p 0.024) and higher HAQ-DI (0.63 vs $0.13, \mathrm{p} 0.018$ ).

\section{Hip joint involvement and progression}

One-fourth $(19,26 \%)$ had hip involvement at baseline X-ray and $27(37 \%)$ had hip involvement at the time of recruitment, after $3.5(2.5-5.5)$ years. Nearly one-fourth $(18,25 \%)$ had progression of hip arthritis. Those with radiological hip arthritis had a longer delay in diagnosis (6 vs 3 years, $p$ 
Table 1 Demographics of patients $(n=73)$

\begin{tabular}{ll}
\hline Parameter & Median (IQR) \\
\hline Male:female & $72: 1(98.6: 1.4)$ \\
Age (years) & $20(18-23)$ \\
Age of onset of disease (years) & $14(11-15)$ \\
Duration of illness (years) & $8(5.5-11)$ \\
Delay in diagnosis (years) & $4(1.75-6)$ \\
Onset of IBP (years from symptom onset) & $0(0-2.5)$ \\
Highest education & \\
Primary (0-5th std) & $2(2.7)$ \\
Secondary (6-10th std) & $3(4.1)$ \\
Higher secondary (11th-12th) & $41(56.2)$ \\
Graduate & $24(32.9)$ \\
Post-graduate & $3(3.5)$ \\
Arthritis & $69(94.5)$ \\
Clinical Hip joint involvement & $23(31.5)$ \\
IBP & $67(91.8)$ \\
Clinical sacroiliitis & $43(59)$ \\
Tarsitis & $43(58.9)$ \\
Uveitis & $13(17.8)$ \\
Enthesitis & $66(90)$ \\
HLA B27 positivity (out of 58) & $56(98)$ \\
Treatment received & \\
NSAIDs alone & $20(27.4)$ \\
DMARDS & $52(71)$ \\
Sulfasalazine & $28(38.4)$ \\
Methotrexate & $12(16.4)$ \\
Both (sulfasalazine and methotrexate) & $4(5.5)$ \\
TNF inhibitors & $2(2.7)$ \\
\hline & \\
\hline
\end{tabular}

$I B P$ inflammatory back pain, ASAS Assessment of Spondyloarthritis International Society criteria, NSAIDS non-steroidal anti-inflammatory drugs, DMARDS disease modifying anti rheumatoid drugs

0.011) than those without it. They also had higher BASDAI, ASDAS-ESR, ASDAS-CRP, BASMI, BASFI, and HAQ DI (Table 2, Fig. 1). Hip arthritis correlated with radiological sacroiliitis $(r=0.330)$, BASDAI $(r=0.368)$, BASMI $(\mathrm{r}=0.473)$, BASFI $(\mathrm{r}=0.476)$, ASDAS-CRP $(0.527)$, ASDAS-ESR (0.445), and HAQ-DI $(r=0.478)$. Hip joint replacement was done in 3 of $27(11 \%)$ patients with hip arthritis.

\section{MRI for active and chronic sacroiliitis and hip involvement}

Of the 30 patients in whom MRI was done, active sacroiliitis changes were seen in three-fourth $(23,77 \%)$ and any one of the chronic changes in $28(93 \%)$. SI joint synovitis and capsulitis were seen in $10 \%$ and $63 \%$, respectively. SI joint enthesitis was seen in $63 \%$ and erosions in $80 \%$. Total edema score was no different between those with or without X-ray sacroiliitis. Those with X-ray sacroiliitis had higher chronic changes, namely subchondral sclerosis (36 vs $0 \%$, p 0.024), and periarticular fat deposition (95 vs 37\%, p 0.000). BM edema/osteitis and synovitis/erosions of hip joints were seen in one-third (10,33\%) (Supplementary Table 1, Fig. 2).

\section{Fulfillment of adult SpA criteria}

Sixty-seven (91\%) patients fulfilled axial ASAS criteria, while $71(97 \%)$ fulfilled peripheral SpA criteria. Threefourths $(54,75 \%)$ fulfilled the modified New York criteria. Fulfillment of modified NY criteria was seen more often in patients with hip arthritis (95 vs 63\%; p 0.002) (Table 2).

\section{Predictors/associations of poor outcomes}

Poor outcomes were seen in 61 (83\%). HLA B27 positivity, presence of IBP, fulfillment of axial and extra-axial ASAS criteria, radiological sacroiliitis progression, and CRP were predictors of poor outcomes in univariate analysis. Radiological hip involvement was also associated with poor outcomes (Table 3). However, none was significant in multivariate analysis.

\section{Discussion}

Nine-tenths of the adults with ERA had active disease even after 8 years of disease. Poor outcomes were seen in threefourths of patients in one or the other domain. Radiological sacroiliitis progression was seen in one-half and hip arthritis progression in one-quarters. Hip involvement, presence of HLA B27, and axial involvement was associated with poorer outcome.

Most were males and HLA B27 positivity was seen almost universally. This is in concordance with world literature on ERA where a prevalence of $60-90 \%$ is reported [21]. The cohort included in the study, thus, was representative of ERA seen at a tertiary care hospital. Nearly all patients fulfilled adult spA criteria (ASAS) and the stricter modified New York criteria for ankylosing spondylitis (AS) was fulfilled by three-fourths of patients. This is again proof of the transition of ERA into AS in adulthood. The prior study by Oliveira-Ramos F et al. had also shown that $95 \%$ of the 80 ERA patients fulfilled adult spA criteria when followed into adulthood over 22.5 years [22].

Nearly $90 \%$ patients had an active disease in adulthood. In a German cohort of 118 ERA, 57\% had persistent active disease in adulthood [23]. Only $23 \%$ had remission and were medication free. The risk of persistence of disease activity was lower for those with peripheral arthritis and enthesitis at disease onset [23]. In the Norwegian study by Flato et al. wherein long-term outcomes of 55 ERA patients were 
Table 2 Differences in baseline characteristics and outcomes between groups based on hip involvement

\begin{tabular}{|c|c|c|c|}
\hline & $\begin{array}{l}\text { Radiological hip } \\
\text { arthritis }(n=27)\end{array}$ & $\begin{array}{l}\text { No radiological hip } \\
\text { arthritis }(n=46)\end{array}$ & $P$ \\
\hline Duration of disease in years median (IQR) & $9(7-11)$ & $6.5(5-10)$ & 0.063 \\
\hline Age in years & $21(19-23)$ & $19.5(18-22.5)$ & 0.137 \\
\hline Age of onset of disease (years) & $13(10-15)$ & $14(12-15)$ & 0.198 \\
\hline Delay in diagnosis (years) & $6(2-9)$ & $3(1-5)$ & 0.011 \\
\hline X-ray interval (years) & $3.5(2-5.5)$ & $3.5(2.5-5.5)$ & 0.377 \\
\hline School years lost (in years) & $1(0.26-2)$ & $0.5(0-2)$ & 0.648 \\
\hline \multicolumn{4}{|l|}{ Clinical features $\mathrm{n}(\%)$} \\
\hline Arthritis & $27(100)$ & $42(91.3)$ & 0.115 \\
\hline Enthesitis & $24(88)$ & $42(91)$ & 0.735 \\
\hline IBP & $24(88)$ & $43(93.9)$ & 0.491 \\
\hline Sacroiliitis & $18(66)$ & $25(54)$ & 0.302 \\
\hline Hip involvement & $17(63)$ & $6(13)$ & $<0.001$ \\
\hline Tarsitis & $18(66)$ & $25(54)$ & 0.335 \\
\hline Uveitis & $4(14)$ & $9(16)$ & 0.609 \\
\hline \multicolumn{4}{|l|}{ Lab parameters } \\
\hline Hemoglobin (g/dl) & $12.1(10.9-13)$ & $12.4(11.5-13.3)$ & 0.391 \\
\hline $\mathrm{ESR}(\mathrm{mm} / \mathrm{h})$ & $26(17-50)$ & $20(14-39)$ & 0.200 \\
\hline CRP (mg/dl) & $3(2.1-6.1)$ & $1.1(0.2-4.23)$ & 0.014 \\
\hline Platelets $\left(\times 10^{5} / \mathrm{dl}\right)$ & $2.3(1.8-2.9)$ & $2.2(1.8-2.7)$ & 0.391 \\
\hline HLA B $27+(\%)$ & $23 / 23(100)$ & $33 / 35(94)$ & 0.227 \\
\hline \multicolumn{4}{|l|}{ Outcome measures } \\
\hline BASDAI & $5(3.2-6.5)$ & $2.6(1.2-4.8)$ & 0.002 \\
\hline ASDAS-CRP & $3.7(2.8-4.3)$ & $2.4(1.6-3.3)$ & 0.001 \\
\hline ASDAS-ESR & $3.1(1.8-2.9)$ & $2.3(1.8-2.9)$ & $<0.001$ \\
\hline BASMI & $2(1.6-4.6)$ & $1.2(0.7-1.8)$ & $<0.001$ \\
\hline BASFI & $3.4(2.1-4.8)$ & $1.3(0.35-2.3)$ & $<0.001$ \\
\hline HAQ DI & $0.88(0.63-1.25)$ & $0.31(0-0.66)$ & $<0.001$ \\
\hline $\mathrm{BASDAI} \geq 4(\%)$ & $19(70)$ & $20(43)$ & $\mathbf{0 . 0 2 8}$ \\
\hline HAQ DI $\geq 0.5(\%)$ & $22(81)$ & $20(43)$ & $<0.001$ \\
\hline Radiological sacroiliitis (\%) & $26(96.3)$ & 33 (71.7) & 0.010 \\
\hline \multicolumn{4}{|l|}{ Progression of radiological } \\
\hline Sacroiliitis (\%) & $13(48)$ & $21(48)$ & 0.995 \\
\hline \multicolumn{4}{|l|}{ Hip arthritis (\%) } \\
\hline \multicolumn{4}{|l|}{ Fulfillment of adult criteria } \\
\hline ASAS criteria & $26(96)$ & $45(97)$ & 0.699 \\
\hline Modified NY criteria & $25(96)$ & $29(63)$ & 0.002 \\
\hline \multicolumn{4}{|l|}{ Treatment received } \\
\hline NSAIDS alone & $7(25)$ & $13(28)$ & 0.829 \\
\hline DMARDS + NSAIDS & $20(74)$ & $32(69)$ & 0.681 \\
\hline
\end{tabular}

$I Q R$ interquartile range, BASDAI Bath Ankylosing Spondylitis Disease Activity Index, BASMI Bath Ankylosing Spondylitis Metrological Index, BASFI Bath Ankylosing Spondylitis Functional Index, HAQ DI Health Assessment Questionnaire Disability Index, ASAS Assessment of Spondyloarthritis International Society criteria, $N Y$ New York criteria, NSAIDS non-steroidal anti-inflammatory drugs, DMARDS disease modifying anti rheumatoid drugs. Bold values are those which were statistically significant compared with oligo or polyarthritis, ERA was found to have lower physical functioning, poorer physical health, and more body pain. Only $4 \%$ had achieved remission and threefourths $(75 \%)$ had reduced spinal flexion. AS in first-degree relative, ankle arthritis in first 6 months, and HLA DRB $1 * 08$ predicted failure to attain disease remission [5], though we have not compared our ERA data with other JIA groups.

A poor outcome, as defined by active disease, disability, or poor functionality, was seen in three-fourths of our patients. Axial involvement, HLA B27 positivity, and 

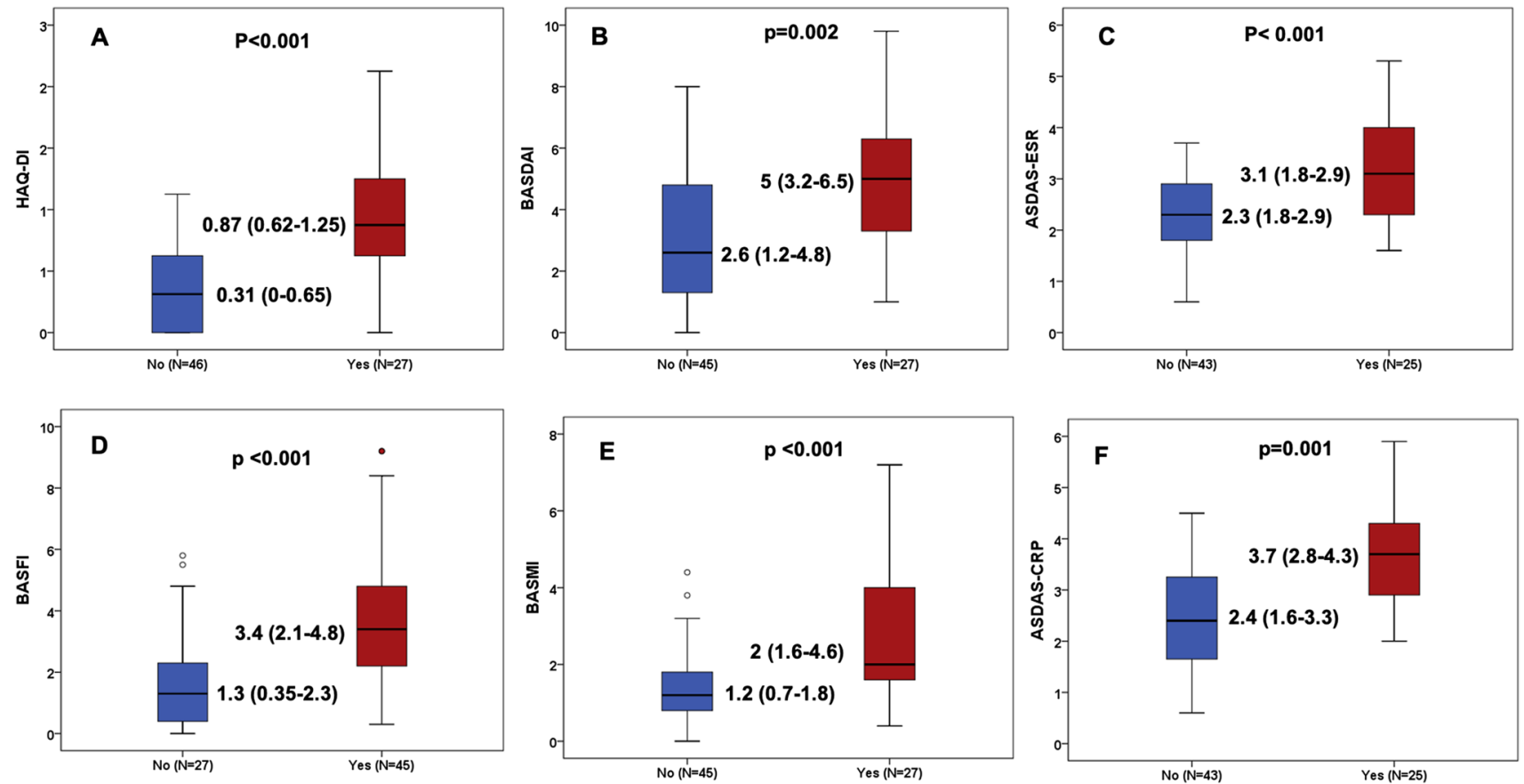

Fig. 1 Hip involvement and outcomes. A HAQ-DI. B BASDAI. C ASDAS-ESR. D BASFI. E BASMI. F ASDAS-CRP

Fig. 2 Sacroiliitis on MRI. A Bone marrow edema on $\mathrm{T} 2 \mathrm{~W}$ FS oblique coronal images and $\mathbf{B}$ corresponding enhancement on T1W FS post-contrast images. C T1FS axial image post-contrast. Capsulitis seen as enhancement along anterior margin of left sacroiliac joint. D Periarticular fat deposition and bony fusion in both sacroiliac joints seen on T1W coronal oblique images

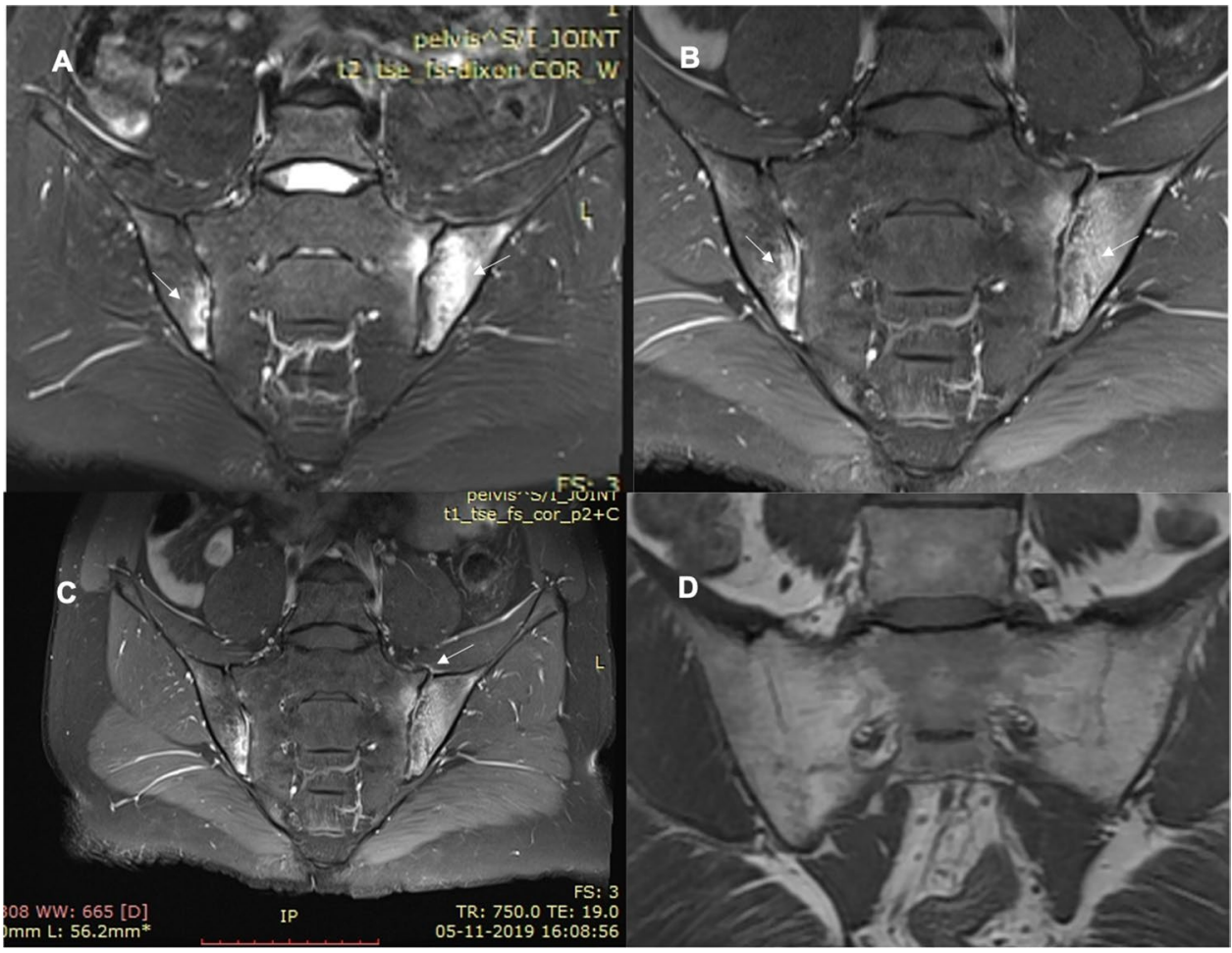

high CRP were also predictors of poor outcomes [24]. Hip involvement was associated with poor outcomes.

There was an average delay in diagnosis of 4 years in our patients of ERA. This could explain why two-thirds had sacroiliitis and one-fifth had hip involvement, to begin with.
Oliveira-Ramos $\mathrm{F}$ et al. studied long-term outcomes of 80 JIA-ERA (among 426 JIA patients) and younger age and longer disease duration were associated with higher disability in that study [22]. However, the age of onset of disease was similar to that has been seen in our study. 
Table 3 Factors predicting poor outcomes

\begin{tabular}{lllll}
\hline & $\begin{array}{l}\text { Patient with poor } \\
\text { outcome }(61)\end{array}$ & $\begin{array}{l}\text { Patient without } \\
\text { poor outcome (12) }\end{array}$ & OR (CI) & p \\
\hline HLA B27 positivity & $51(83)$ & $5(41)$ & $7.1(1.8-27)$ & 0.002 \\
IBP & $58(95)$ & $9(75)$ & $6.4(1.1-36)$ & 0.021 \\
Fulfill axial ASAS criteria & $58(95)$ & $9(75)$ & $6.4(1.1-36)$ & 0.021 \\
Fulfill extra-axial ASAS criteria & $61(100)$ & $10(83)$ & $29(1.3-654)$ & 0.001 \\
Radiological hip involvement & $26(42)$ & $1(8)$ & $6(1.2-28)$ & 0.025 \\
Sacroiliitis progression & $25(41)$ & $9(75)$ & $0.23(0.05-0.94)$ & 0.045 \\
CRP (mg/dl) & $2.55(1-6.2)$ & $0.62(0.02-1.6)$ & - & 0.003 \\
\hline
\end{tabular}

Poor outcomes defined by those patients with either BASDAI $\geq 4$, or ASDAS-CRP $\geq 2.1$, or BASFI $\geq 0.9$, or HAQ-DI $\geq 0.5$

Blocked variables are significant in binary logistic regression

$O R$ odds ratio, $C I$ confidence interval, IBP inflammatory back pain, ASAS Assessment of Spondyloarthritis International Society criteria, ESR erythrocyte sedimentation rate
Those with hip involvement had higher BASDAI, ASDAS, BASMI, BASFI, and HAQ-DI. Prior studies have observed a correlation of HAQ-DI and persistence of active disease in ERA [22, 23]. JADI-A correlates with traditional outcomes in ERA, but underestimates joint damage, and does not assess enthesitis and spinal limitation [4]. Adult outcome measures had good construct validity, discriminative capacity, and sensitivity to change, and had good correlation with JSpADA in a study by Zanwar et al. [25]. Hence, we had used the same outcome measures in our study.

Interestingly, only three patients (11\%) had undergone hip joint replacement in those with hip arthritis. This could explain the higher disability in the remaining cohort. The reason for not undergoing hip replacement despite disability could be financial or social. In a study by Jadon et al. [26], juvenile ankylosing spondylitis were more likely than adult ankylosing spondylitis to proceed to hip arthroplasty, revision, and re-revision surgeries. There was no linear relationship between age of onset of AS and likelihood for surgery. Our study had a shorter follow-up duration in comparison (8vs23 years) and many more patients might need hip replacement on longer follow-up, as seen in the study by Malviya et al. [27] wherein 75\% of JIA needed a surgery after 40 years of disease. Furthermore, a longer delay in diagnosis ( 8 years) was also noted in that study.

Progression of radiological sacroiliitis and hip arthritis was seen in one-half and one-quarter of our patients. This is due to persistent disease activity and damage accrued over time. Nearly all had chronic sacroiliitis changes in MRI and three-fourths had persisting active changes in the form of bone marrow edema/osteitis in the study population. Most were treated with NSAIDs and DMARDs alone or in combination. This is due to a lack of access to biologics due to financial reasons. High ESR and hip arthritis in the first 6 months predicted the development of sacroiliitis in the study by Flato et al. [5]. Persistence of IBP was seen in half of the patients with IBP at disease onset in the German cohort [23]. In our study, those with sacroiliitis had higher CRP, radiological hip involvement, and higher HAQ-DI in comparison with those without sacroiliitis.

There was only half a year of school lost due to the disease suggesting that schooling is not much affected [28]. In a study by Malviya et al., functional disability and educational attainment predicted successful employability in JIA patients in adulthood and was uninfluenced by the JIA subtype [27, 29]. Hip involvement, presence of HLA B27, and axial involvement were associated with poorer outcome. In adults, HLA B27 has been found to be a severity marker [28]. HLA B27 predicted chronic course, sacroiliitis, and hip arthritis in boys after 8 years of follow-up in a study [30].

The strength of the study is a good sample size, radiological outcomes along with functional outcomes. The limitations are lack of MRI in all patients, significant damage at the time of diagnosis due to delay in diagnosis, non-usage of biologics in today's era, and less female representation. Furthermore, only $50 \%$ of those who were invited to participate in the study turned up due to the ongoing pandemic and the travel restrictions. Being a tertiary care center, one-third of patients followed up at their local place. Furthermore, in 72 patients, baseline radiographs were not done as the physicians deemed it unnecessary due to absence of IBP. This could have resulted in a selection bias in inclusion of patients in this study. An inception cohort with early disease may help us know the outcome of ERA in resourceconstrained countries better.

\section{Conclusion}

Nine-tenths of the adults with ERA had an active disease even after 8 years of disease. Poor outcomes were seen in three-fourths with hip involvement, axial involvement, and HLA-B27 positivity as predictors in univariate analysis. Radiological sacroiliitis progression was seen in one-half 
and hip arthritis progression in one-quarters despite treatment. Most ERA patients in adulthood fulfilled the criteria for AS.

Supplementary Information The online version contains supplementary material available at https://doi.org/10.1007/s10067-021-05807-3.

Acknowledgements We acknowledge the help provided by $\mathrm{Mr}$ Abhishek Samuel and Mr Akash Yadav, employed in ICMR project for the conduct of the study.

Author contribution AA was involved in ideation. NR, AA, NM, NJ, and SM were involved in data collection and interpretation. NR and AA in data analysis. All authors contributed in manuscript preparation and agree with the submitted version.

Funding Intramural grant from Sanjay Gandhi Postgraduate Institute of Medical Sciences to AA. Partly funded by ICMR project number 5/7/1652/CH/adhoc/2019-RBMH\&CH.

Data availability Data can be made available at reasonable request to the corresponding author.

\section{Declarations}

Conflict of interest None.

\section{References}

1. Petty RE, Southwood TR, Manners P, Baum J, Glass DN, Goldenberg J et al (2004) International League of Associations for Rheumatology classification of juvenile idiopathic arthritis: second revision, Edmonton, 2001. J Rheumatol 31(2):390-392

2. Mistry RR, Patro P, Agarwal V, Misra D (2019) Enthesitis-related arthritis: current perspectives. Open Access Rheumatol 11:19-31

3. Bou Antoun M, Adamsbaum C, Semerano L, Koné-Paut I, RossiSemerano L (2017) Clinical predictors of magnetic resonance imaging-detected sacroiliitis in children with enthesitis related arthritis. Joint Bone Spine 84(6):699-702

4. Sarma P, Misra R, Aggarwal A (2008) Outcome in patients with enthesitis related arthritis (ERA): juvenile arthritis damage index (JADI) and functional status. Pediatr Rheumatol 6(1):18

5. Flat $\varnothing$ B, Hoffmann-Vold A-M, Reiff A, Øy Førre, Lien G, Vinje O (2006) Long-term outcome and prognostic factors in enthesitis-related arthritis: a case-control study. Arthritis Rheum 54(11):3573-82

6. Zochling J (2011) Measures of symptoms and disease status in ankylosing spondylitis: Ankylosing Spondylitis Disease Activity Score (ASDAS), Ankylosing Spondylitis Quality of Life Scale (ASQoL), Bath Ankylosing Spondylitis Disease Activity Index (BASDAI). Bath Ankylosing Sp Arthritis Care Res 63(S11):S47-58

7. Fernández-Espartero C, de Miguel E, Loza E, Tomero E, Gobbo M, Descalzo MA et al (2014) Validity of the Ankylosing Spondylitis Disease Activity Score (ASDAS) in patients with early spondyloarthritis from the Esperanza programme. Ann Rheum Dis 73(7):1350-1355

8. Bruce B, Fries JF (2003) No title found. Health Qual Life Outcomes 1(1):20
9. Sieper J, Rudwaleit M, Baraliakos X, Brandt J, Braun J, BurgosVargas R et al (2009) The Assessment of SpondyloArthritis international Society (ASAS) handbook: a guide to assess spondyloarthritis. Ann Rheum Dis 68(Suppl 2):ii1-44

10. Wanders AJB, Landewé RBM, Spoorenberg A, Dougados M, van der Linden S, Mielants $\mathrm{H}$ et al (2004) What is the most appropriate radiologic scoring method for ankylosing spondylitis? A comparison of the available methods based on the Outcome Measures in Rheumatology Clinical Trials filter. Arthritis Rheum 50(8):2622-2632

11. Kunjir V, Venugopalan A, Chopra A (2010) Profile of Indian patients with juvenile onset chronic inflammatory joint disease using the ILAR classification criteria for JIA: a communitybased cohort study. J Rheumatol 37(8):1756-1762

12. Aggarwal A, Misra R (1994) Juvenile chronic arthritis in India: is it different from that seen in Western countries? Rheumatol Int 14(2):53-56

13. Consolaro A, Giancane G, Alongi A, van Dijkhuizen EHP, Aggarwal A, Al-Mayouf SM et al (2019) Paediatric Rheumatology International Trials Organisation. Phenotypic variability and disparities in treatment and outcomes of childhood arthritis throughout the world: an observational cohort study. Lancet Child Adolesc Health 3(4):255-263

14. Terjesen T, Gunderson RB (2012) Radiographic evaluation of osteoarthritis of the hip: an inter-observer study of 61 hips treated for late-detected developmental hip dislocation. Acta Orthop 83(2):185-189

15. Banegasillescas ME, López Menéndez C, Rozas Rodríguez ML, Fernández Quintero RM (2014) Nuevos criterios ASAS para el diagnóstico de espondiloartritis. Diagnóstico de sacroileítis por resonancia magnética. Radiología 56(1):7-15

16. Sharma N, Sharma V, Masood T, Nautiyal SC, Sailwal S, Singh RK et al (2013) Usage of conventional PCR technology for the detection of HLA-B27 allele: a significant molecular marker of ankylosing spondylitis. Indian J Clin Biochem 28(2):189-192

17. Wariaghli G, Allali F, Berrada K, Idrissi Z, Hmamouchi I, Abouqal R et al (2012) Normative values for the bath ankylosing spondylitis functional index in the general population compared with ankylosing spondylitis patients in Morocco. BMC Musculoskelet Disord 13(1):40

18. Linden SVD, Valkenburg HA, Cats A (1984) Evaluation of diagnostic criteria for ankylosing spondylitis. Arthritis Rheum 27(4):361-368

19. Cohen J-D, Cunin P, Farrenq V, Oniankitan O, Carton L, Chevalier X et al (2006) Estimation of the Bath Ankylosing Spondylitis Disease Activity Index cutoff for perceived symptom relief in patients with spondyloarthropathies. J Rheumatol 33(1):79-81

20. STROBE_checklist_v4_cross-sectional.pdf [Internet]. [cited 2020 Oct 7]. Available from: https://www.strobe-statement. org/fileadmin/Strobe/uploads/checklists/STROBE_checklist_ v4_cross-sectional.pdf

21. Hersh AO, Prahalad S (2015) Immunogenetics of juvenile idiopathic arthritis: a comprehensive review. J Autoimmun 64:113-124

22. Oliveira-Ramos F, Eusébio M, Martins M, F, Mourão AF, Furtado C, Campanilho-Marques R, et al (2016) Juvenile idiopathic arthritis in adulthood: fulfilment of classification criteria for adult rheumatic diseases, long-term outcomes and predictors of inactive disease, functional status and damage. RMD Open 2(2): $\mathrm{e} 000304$

23. Weib A, Minden K, Listing J, Foeldvari I, Sieper J, Rudwaleit M (2017) Course of patients with juvenile spondyloarthritis during 4 years of observation, juvenile part of GESPIC. RMD Open 3:e000366

24. Burgos-Vargas R, Clark P (1989) Axial involvement in the seronegative enthesopathy and arthropathy syndrome 
and its progression to ankylosing spondylitis. J Rheumatol 16(2):192-197

25. Zanwar A, Phatak S, Aggarwal A (2018) Prospective validation of the Juvenile Spondyloarthritis Disease Activity Index in children with enthesitis-related arthritis. Rheumatology 57(12):2167-2171

26. Jadon DR, Shaddick G, Jobling A, Ramanan AV, Sengupta R (2015) Clinical outcomes and progression to orthopedic surgery in juvenile- versus adult-onset ankylosing spondylitis: outcomes in juvenile- versus adult-onset AS. Arthritis Care Res 67(5):651-657

27. Malviya A, Johnson-Lynn S, Avery P, Deehan D, Foster H (2009) Juvenile idiopathic arthritis in adulthood and orthopaedic intervention. Clin Rheumatol 28(12):1411-1417

28. Bouaddi I, Rostom S, El Badri D, Hassani A, Chkirate B, Amine B et al (2013) Impact of juvenile idiopathic arthritis on schooling. BMC Pediatr 13(1):2
29. Malviya A, Rushton SP, Foster HE, Ferris CM, Hanson H, Muthumayandi K et al (2012) The relationships between adult juvenile idiopathic arthritis and employment. Arthritis Rheum 64(9):3016-3024

30. Berntson L, Nordal E, Aalto K, Peltoniemi S, Herlin T, Zak M et al (2013) HLA-B27 predicts a more chronic disease course in an 8-year followup cohort of patients with juvenile idiopathic arthritis. J Rheumatol 40(5):725-731

Publisher's note Springer Nature remains neutral with regard to jurisdictional claims in published maps and institutional affiliations. 